\title{
How drug resistance takes shape
}

\section{Mutations in a hormone receptor can lead to therapeutic resistance by making it less able to bind and respond to hormone blocking drugs and by making it active, even when the hormome is not present.}

\section{RINATH JESELSOHN AND MYLES BROWN}

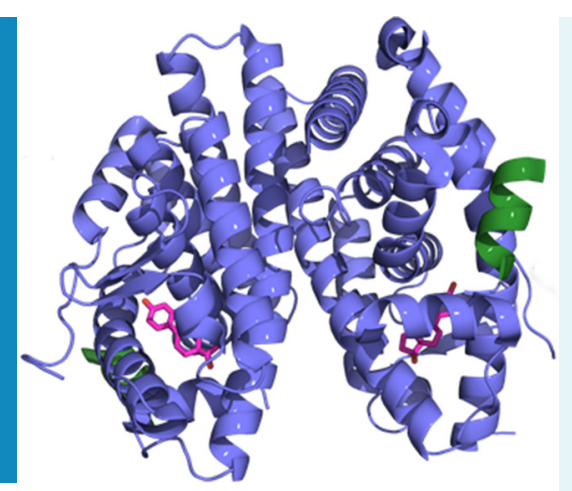

\author{
Related research article Fanning SW, Mayne \\ CG, Dharmarajan V, Carlson KE, Martin TA, \\ Novick SJ, Toy W, Green B, Panchamukhi S, \\ Katzenellenbogen BS, Tajkhorshid E, Griffin \\ PR, Shen Y, Chandarlapaty S, \\ Katzenellenbogen JA, Greene GL. 2016. \\ Estrogen receptor alpha somatic mutations \\ Y537S and D538G confer breast cancer \\ endocrine resistance by stabilizing the \\ activating function-2 binding conformation. \\ eLife 5:e12792. doi: 10.7554/eLife.12792 \\ Image Estrogen (pink), followed by a co- \\ activator (green), bind to estrogen receptor \\ alpha (purple) in order to activate it
}

\footnotetext{
(c) Copyright Jeselsohn and Brown. This article is distributed under the terms of the Creative Commons Attribution License, which permits unrestricted use and redistribution provided that the original author and source are credited.
}

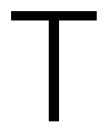
he majority of breast cancers are hormone receptor positive and are sensitive to the steroid hormone estrogen. This hormone binds to and activates a transcription factor known as estrogen receptor alpha $(E R \alpha)$, and drugs that reduce the production of estrogen or directly block estrogen binding by $E R \alpha$ can halt the growth of estrogensensitive cancers. However, in many cases, these endocrine therapies eventually stop working because the cancer cells develop resistance to the drugs. Recently, this resistance has been linked to a number of mutations in the gene for $E R \alpha$ that are almost exclusively found in patients who have received hormone therapy. The two most prevalent mutations to have been identified are the missense mutations Y537S and D538G. (Toy et al., 2013; MerenbakhLamin et al., 2013; Robinson et al., 2013; Jeselsohn et al., 2014 ).

The ER $\alpha$ mutations affect the part of the protein called the ligand-binding domain. Studies in breast cancer cell lines show that these mutations result in ER $\alpha$ activity, even in the absence of estrogen, and that they cause relative resistance to tamoxifen and other drugs that directly target ER $\alpha$. Now, in eLife, Geoffrey Greene of the University of Chicago and colleagues - including Sean Fanning, Christopher Mayne and Venkatasubramanian Dharmarajan as joint first authors - report new insights into the effects that the two mutations have on the structure of ER $\alpha$ (Fanning et al., 2015). They also explore how these mutations can lead to drug resistance.

The ligand-binding domain of ER $\alpha$ consists of three layers of $\alpha$-helices. The final helix, known as helix-12, acts as a molecular switch that changes position when estrogen binds to the domain. This enables co-activator proteins, such as the steroid receptor coactivator 3 (SRC3), to bind to and activate ER $\alpha$. A previous study found that the ligand-binding domain from an ER $\alpha$ mutant known as Y537S has a structure that strongly resembles the wild-type domain when it is bound to estrogen (Nettles et al., 2008). This mutation stabilizes helix-12 in a conformation that allows the coactivator to bind (even in the absence of estrogen) by forming a hydrogen bond with another amino acid in ER $\alpha$. 
The crystal structure of the D538G mutant remained unknown and molecular modeling provided limited insight as to how this mutation allowed ER $\alpha$ to be active in the absence of estrogen. Furthermore, it was not clear how any of the mutations render cancer cells more resistant to drugs that target ER $\alpha$. Some researchers proposed that the drug resistance was caused by decreased binding affinity to the ER $\alpha$ mutants, but few studies have been carried out to test this hypothesis.

Fanning et al. - who are based at Chicago, the University of Illinois at Urbana-Champaign, the Scripps Research Institute, the Memorial Sloan Kettering Cancer Center and Texas A\&M University - addressed these questions by performing comprehensive biophysical and crystallographic studies on the Y537S and D538G mutations. This information is critical for the development of new molecules that target these mutations.

Fanning et al. show that SRC3 only binds to wild-type $E R \alpha$ in the presence of estrogen, while the Y537S and D538G mutants are able to recruit SRC3 in the absence of the hormone. In addition, ligand-binding assays demonstrate that the affinity for tamoxifen-mutant binding is lower than the affinity for tamoxifen-wild type binding. Taken together, the mutations stabilize the active form of ER $\alpha$ and make it harder for anti-cancer drugs to bind to it. However, the addition of estrogen still increased the ability of SRC3 to bind to both mutants, which suggests that depriving tumors of estrogen may still be important in treating cancers with these mutations.

Next, Fanning et al. obtained X-ray crystal structures of the ligand-binding domain from the D538G mutant on its own, and when it was bound to estrogen or tamoxifen. As expected, helix-12 in this mutant was more stable in the conformation that allows SRC3 to bind even in the absence of estrogen. This stability, however, is structurally different from that observed in the Y537S mutant and is more subtle. In addition, in the absence of estrogen, SRC3 binds to the Y537S mutant with an affinity that is higher than when it binds to the D538G mutant. These differences between the two mutations may have clinical implications, as recent data suggests that they may be associated with different outcomes in cancer patients (Chandarlapaty, 2015). However, additional studies are needed to fully understand how important these differences are.

In the presence of tamoxifen, the ligand-binding domain of the D538G mutant adopts a conformation that is different to that of the wild type domain. This difference is mainly due to changes in a loop that connects helix-11 and helix-12, and leads to a decrease in the inhibitory activity of tamoxifen. Likewise, computational modeling suggests that the Y537S mutation also induces a conformational change in the ligand-binding domain that reduces the ability of tamoxifen to inhibit ER $\alpha$ activity. Thus, resistance to tamoxifen stems from a combination of the drug being less likely to bind to the mutant domains and being less effective when it does bind.

The work of Fanning et al. significantly advances our understanding of the link between structural alterations of the ER $\alpha$ mutant and drug resistance, suggesting that new drugs will be needed to overcome the resistance caused by these mutations. These new drugs will need to bind to the mutant domains with higher affinity than existing drugs and be able to either stabilize helix-12 in the conformation that prevents SRC3 or other co-activators from binding, or promote the degradation of ER $\alpha$. Future studies will also need to focus on the mutation known as E3800 that is also detected in breast cancer patients with resistant disease and may have similar effects to the mutations studied by Fanning et al.

Rinath Jeselsohn is in the Center for Functional Cancer Epigenetics and the Department of Medical Oncology, Dana-Farber Cancer Institute, Boston, United States, and the Department of Medicine, Harvard Medical School, Boston, United States Myles Brown is in the Center for Functional Cancer Epigenetics and the Department of Medical Oncology, Dana-Farber Cancer Institute, Boston, United States, and the Department of Medicine, Harvard Medical School, Boston, United States myles_brown@dfci.harvard.edu

Competing interests: The authors declare that no competing interests exist.

Published 24 March 2016

\section{References}

Chandarlapaty S, Sung P, Chen D, He W, Samoila A, You D, Bhatt T, Patel P, Voi M, Gnant M, et al.2015. cfDNA analysis from BOLERO-2 plasma samples identifies a high rate of ESR1 mutations: Exploratory analysis for prognostic and predictive correlation of mutations reveals different efficacy outcomes of endocrine therapy-based regimens. San Antonio Breast Cancer Symposium. abstract S2-07. Jeselsohn R, Yelensky R, Buchwalter G, Frampton G, Meric-Bernstam F, Gonzalez-Angulo AM, FerrerLozano J, Perez-Fidalgo JA, Cristofanilli M, Gómez H, et al.2014. Emergence of constitutively active estrogen 
receptor- $\alpha$ mutations in pretreated advanced estrogen receptor-positive breast cancer. Clinical Cancer Research 20:1757-1767. doi: 10.1158/1078-0432.CCR13-2332

Merenbakh-Lamin K, Ben-Baruch N, Yeheskel A, Dvir A, Soussan-Gutman L, Jeselsohn R, Yelensky R, Brown M, Miller VA, Sarid D, et al.2013. D538G mutation in estrogen receptor- $\alpha$ : A novel mechanism for acquired endocrine resistance in breast cancer. Cancer Research 73:6856-6864. doi: 10.1158/0008-5472.CAN-13-1197 Nettles KW, Bruning JB, Gil G, Nowak J, Sharma SK, Hahm JB, Kulp K, Hochberg RB, Zhou H,

Katzenellenbogen JA, et al.2008. NF $\kappa$ B selectivity of estrogen receptor ligands revealed by comparative crystallographic analyses. Nature Chemical Biology 4: 241-247. doi: 10.1038/nchembio.76

Robinson DR, Wu YM, Vats P, Su F, Lonigro RJ, Cao $X$, Kalyana-Sundaram S, Wang R, Ning Y, Hodges L, et al.2013. Activating ESR1 mutations in hormoneresistant metastatic breast cancer. Nature Genetics 45: 1446-1451. doi: 10.1038/ng.2823

Toy W, Shen Y, Won H, Green B, Sakr RA, Will M, Li Z, Gala K, Fanning S, King TA, et al.2013. ESR1 ligandbinding domain mutations in hormone-resistant breast cancer. Nature Genetics 45:1439-1445. doi: 10.1038/ ng. 2822 